\title{
Análise geográfica para a cidade de Arapiraca/AL sob a perspectiva dos indicadores de Vulnerabilidade Socioambiental ${ }^{1}$
}

\section{Geographic analysis for the city of Arapiraca/AL from the perspective of socio-environmental vulnerability indicators}

\author{
Juliete dos Santos \\ Mestre em Dinâmicas Territoriais e Cultura-ProdiC/UNEAL \\ Membra do Laboratório de Estudos sobre Vulnerabilidade Socioambiental-LEVSA \\ Universidade Estadual de Alagoas-UNEAL, Brasil \\ juh-lietesantos1@hotmail.com \\ Leandro Antonio de Oliveira \\ Mestre em Dinâmicas Territoriais e Cultura-ProdiC/UNEAL \\ Membro do Laboratório de Estudos sobre Vulnerabilidade Socioambiental-LEVSA \\ Universidade Estadual de Alagoas-UNEAL, Brasil \\ leo.juh30@gmail.com
}

José Lidemberg de Sousa Lopes

Doutor em Geografia pela Universidade Federal do Ceará-UFC. Professor assistente da Universidade Estadual de Alagoas-UNEAL - Campus V e do Programa de Pós-Graduação em Dinâmicas Territoriais e Cultura-ProdiC Coordenador do laboratório de estudos sobre vulnerabilidade socioambiental-LEVSA, Brasil jlidemberg@yahoo.com.br

\section{Resumo}

O presente trabalho avaliou o nível de vulnerabilidade socioambiental da cidade de Arapiraca no estado de Alagoas. Foi adaptado os aspectos metodológicos das pesquisas de Lopes (2013) e Adger (2006) para a criação de critérios e indicadores afim de identificar o Índice de Vulnerabilidade Socioambiental (IVSA) da cidade. Em uma escala de 0,0 (valor mínimo) a 1,0 (valor máximo) a análise dos indicadores encontrou um índice de 0,35 que coloca a cidade de Arapiraca em um nível de baixa vulnerabilidade. De acordo com o nosso trabalho, o critério que influência decisivamente no Índice de Vulnerabilidade Socioambiental de Arapiraca-AL, é o de sensibilidade. Esse critério, avaliou a dimensão risco social com as características da população com o intuito de demostrar a fragilidade quando exposto a um dano, possuindo a maior quantidade de indicadores, sete no total. Os valores obtidos por cada indicador foram satisfatórios e inevitavelmente se sobressaíram em relação aos demais. Conclui-se, que na cidade de Arapiraca, populações socialmente vulneráveis tendem a se localizar em áreas ambientalmente vulneráveis.

Palavras-chave: Vulnerabilidade, Indicadores, Risco social.

\begin{abstract}
This work evaluated whether the level of socio-environmental vulnerability in the city of Arapiraca in the state of Alagoas. The methodological aspects of the research by Lopes (2013) and Adger (2006) were adapted to create criteria and indicators in order to identify the city's Socioenvironmental Vulnerability Index (IVSA). On a scale of 0.0 (minimum value) to 1.0 (maximum value), the analysis of the indicators found an index of 0.35 , which places the city of Arapiraca at a low vulnerability level. According to our work, the criterion that decisively influences ArapiracaAL Socio-Environmental Vulnerability Index is that of sensitivity. This criterion evaluated the

\footnotetext{
1 Trabalho desenvolvido com o apoio financeiro da Coordenação de Aperfeiçoamento de Pessoal de Nível Superior-
} CAPES.
\end{abstract}


social risk dimension, with the characteristics of the population in order to demonstrate fragility when exposed to damage, having the largest number of indicators, seven in total. The values obtained for each indicator were satisfactory and inevitably stood out concerning the others. In conclusion, in the city of Arapiraca, socially vulnerable populations tend to be located in environmentally vulnerable areas.

Keywords: Vulnerability, Indicators, Social risk.

\section{INTRODUÇÃO}

Os problemas socioambientais urbanos têm nos últimos anos, ganhado ênfase nos debates acadêmicos, tendo em vista o rápido crescimento dos grandes centros habitacionais. Mendonça e Leitão (2008), afirmam que essa urbanização generalizada que marca o presente momento da humanidade promove a acumulação de homens e atividades em espaços restritos, fazendo das cidades lugares altamente vulneráveis a qualquer agente perturbador, quer seja exógeno ou endógeno, natural ou técnico.

Nesse contexto, observamos o notório crescimento populacional que vivencia a cidade de Arapiraca. Conforme apresenta as pesquisas desenvolvidas por Morais et al. (2014), a cultura do fumo teve um importante papel no desenvolvimento municipal. Todavia, as várias crises do setor fumageiro, decorrentes da política antitabagista provocou o declínio dessa atividade. Após a decadência, o município vislumbrou na sua localização central no Estado de Alagoas uma forma de suprir as necessidades deixada pela agricultura, o comercio.

Esse destaque, apresenta uma nova realidade para o município, segundo o último Censo (IBGE, 2010), o município possui 214.006 habitantes, sendo que, 84,8\% da população encontra-se na zona urbana, ou seja, 181.481 mil pessoas. Já a porção menor, os 32.525 habitantes estão localizados na zona rural. Comparando com os dados dos censos anteriores, observamos que no Censo dos anos 2000, o município tinha 186. 755 habitantes, destes 152.354 estavam na zona urbana (IBGE, 2000). Já no Censo de 1991, Arapiraca possuía 166.351 habitantes, sendo 130.963 pessoas localizadas na zona urbana (IBGE, 1991). Esse aumento populacional se depara muitas vezes com um cenário evidenciado por Mendonça e Leitão (2008), segundo os autores, no Brasil, as populações menos favorecidas, devido a problemas decorrentes da especulação imobiliária, são, muitas vezes, impelidas a ocupar locais insalubres e expostos a vulnerabilidade.

A cidade de Arapiraca está localizada na porção central do Estado de Alagoas a cerca de $130 \mathrm{~km}$ da capital, Maceió. De acordo com os dados do IBGE (2010), o município ocupa uma área de cerca de $345,655 \mathrm{Km}^{2}\left(1,32 \%\right.$ de Alagoas) e está situada segundo a PMA (2007) a 9 $75^{\circ}$ ' 25," de latitude sul e $36^{\circ} 60^{\prime} 11^{\prime}$ ' de longitude oeste. A figura 1 demonstra a localização da zona urbana de Arapiraca e, respectivamente, a divisão de seu território em 38 bairros, no ano de 2010. 


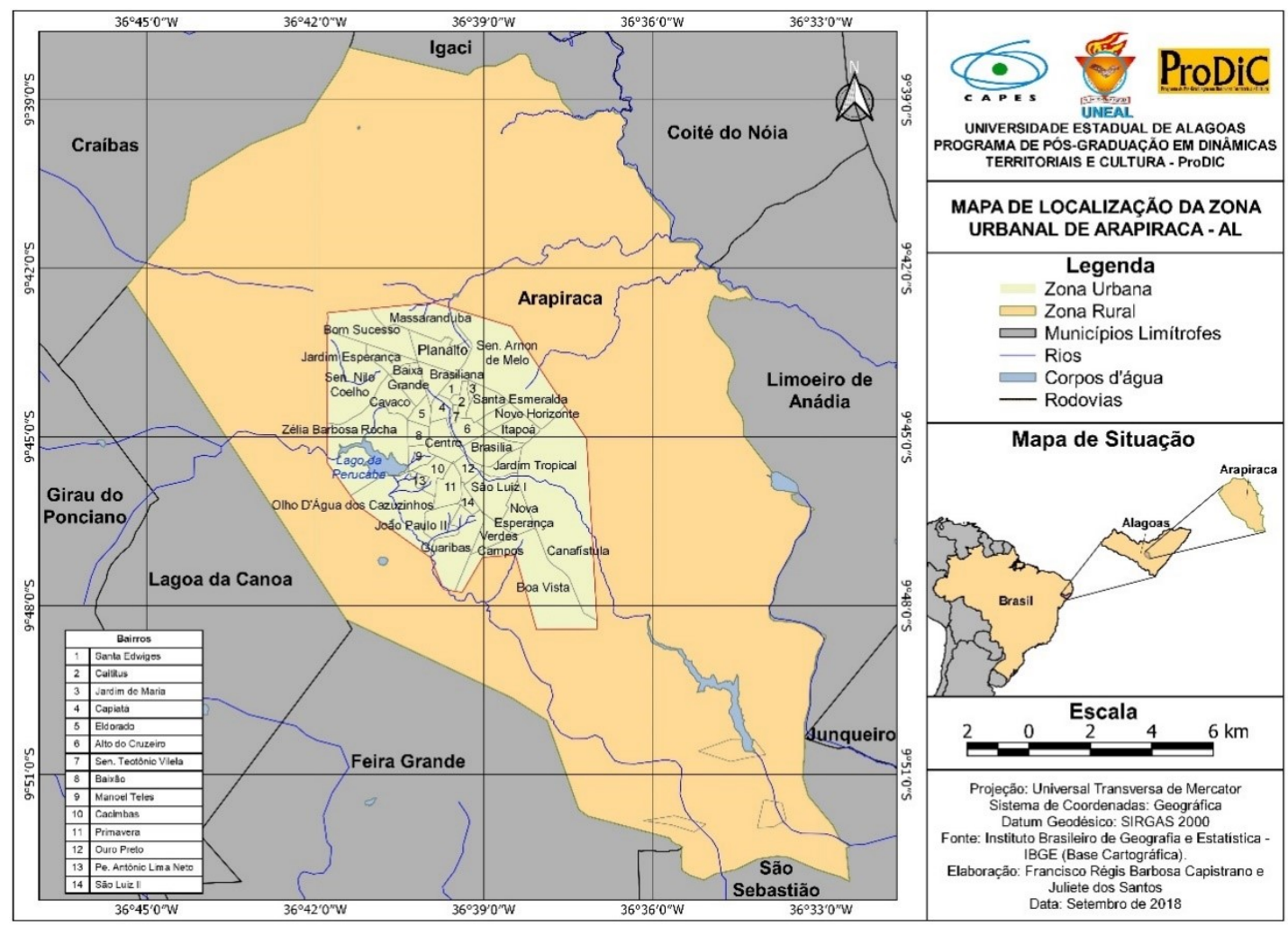

Figura 1 - Localização da Zona Urbana de Arapiraca-AL.

Fonte: Autores, 2018.

Ao longo dos anos, os estudos sobre o nível de vulnerabilidade da população são importantes por buscar identificar os sujeitos ou as áreas que, segundo Deschamps (2009, p.11), são mais propensas a enfrentar circunstâncias adversas. Logo, o crescimento acelerado da população desencadeia vários problemas, tendo em vista que as populações mais carentes as margens dos serviços públicos ocupam regiões improprias à habitação. Com base nessa análise, Souza (2005), explica que o fato da população urbana aumentar em proporção e em tamanho absoluto, faz com que as atenções se voltem para os problemas urbanos. Segundo o autor, “[...] em uma sociedade capitalista e principalmente em países em desenvolvimento, os impactos ambientais são de difícil domesticação e resultam de uma necessidade de produzir cada vez mais [...]” (SOUZA, 2005, p. 94/95).

Nessa perspectiva, Deschamps (2009), evidencia que é de extrema importância desenvolver uma análise que não se atente apenas as desigualdades sociais, mas, que verifique como estas se associam com situações de desigualdade ambiental, ou seja, tratar da questão mais específica de vulnerabilidade socioambiental. No entanto, para sua efetivação, é imprescindível delimitar e identificar as regiões que apresentam essas características, uma vez que, populações com um menor poder aquisitivo historicamente tendem a ocupar áreas que são ambientalmente vulneráveis o que para a autora seria expô-las "a um outro processo intraurbano: o da segregação ambiental" (DESCHAMPS, 2009, p. 07). 
É nesse aspecto, que trabalhos recentes como os estudos elaborados por Lopes (2013), Adger (2006) e Deschamps (2004) trazem novas perspectivas e metodologias que permitem uma melhor compreensão desse ambiente complexo que se tornou os espaços urbanos.

Portanto, o presente estudo, avaliou o nível de vulnerabilidade socioambiental da cidade de Arapiraca/AL. Paralelamente, a pesquisa elaborou um Índice de Vulnerabilidade Socioambiental (IVSA), mapeou as áreas vulneráveis e comparou os dados dos Censos demográficos dos anos 2000 e 2010 .

\section{ENTENDENDO A VULNERABILIDADE SOCIOAMBIENTAL}

A vulnerabilidade é defendida por Mitchell (1989) como o potencial de perda de um sistema. Nesse contexto, se observa que vários aspectos podem influenciar direta ou indiretamente os riscos em que o ser humano, em grupo ou individual, está exposto no seu dia a dia. Assim, “a vulnerabilidade envolve um conjunto de fatores que pode diminuir ou aumentar os riscos aos quais o ser humano, individualmente ou em grupo, está exposto em diversas circunstâncias de sua vida [...]" (LOPES, 2013, p. 28/29). Segundo Zanella et al. (2009), a vulnerabilidade se encontra diretamente relacionada com grupos vulneráveis (populações) que, por determinadas contingências são mais propensos a uma resposta negativa quanto à ocorrência de algum evento adverso.

Devido ao caráter interdisciplinar apresentado pelos autores, é importante antes de analisar a vulnerabilidade se questionar sobre os sujeitos que farão parte de sua pesquisa. Por isso, para Liverman (1994), é necessário entender vulnerabilidade a quê? Onde e quem está ou é vulnerável?

Dentro da referida pesquisa, trabalhamos a vulnerabilidade em três dimensões: social; ambiental e socioambiental. A primeira, nos últimos anos, tem sido utilizada por muitos estudiosos e organismos internacionais que trabalham analisando a perspectiva da pobreza. Nesse contexto, Marandola Jr. e Hogan (2005), observaram que as características socioeconômicas das populações nas áreas de risco consistem em um componente fundamental quando estamos discutindo sobre vulnerabilidade social. Para os autores, "fatores como a distribuição de renda, escolaridade, raça, tipo de ocupação, entre outros, são te extrema importância para analisar a vulnerabilidade em seu caráter social.

Deste modo, Zanella et al. (2009), destaca que esses fatores, vão tornar as pessoas ou grupos mais ou menos vulneráveis, ou seja, com capacidade de superar ou minimizar as dificuldades e riscos, e de aproveitar as oportunidade para melhorar a sua situação de bem-estar. E essa relevância vincula-se em uma correlação forte entre áreas de risco ambiental e grupos de renda mais baixa e com consideráveis níveis de dificuldades sociais. Para Zanella et al. (2009): 
[...] Os grupos sociais de maior renda ocupam os ambientes de amenidade sociais e ambientais e com melhor infraestrutura e serviços, enquanto os de menor poder aquisitivo, os mais vulneráveis, tendem a se localizar nas chamadas áreas de risco, ou seja, áreas de maior exposição a situações insalubres (contaminação de água, do solo, e do ar) e inseguras (riscos de acidentes de diversos tipos) (ZANELLA et al., p. 193).

Para a autora, a vulnerabilidade social está relacionada à grupos vulneráveis que por determinadas questões (poder aquisitivo, localização, educação etc.) são menos propensos a uma resposta positiva sobre a ocorrência de um evento adverso.

Já para entender a perspectiva ambiental, Lopes (2013), expõe que a "vulnerabilidade a nível ambiental pode ser compreendida como o risco a degradação do meio ambiente”. Segundo o autor, há necessidade de analisar fatores, como erosão do solo, perda da biodiversidade, assoreamento de rios, contaminação dos recursos hídricos e solos, para que se possa fazer um estudo mais apurado do espaço socioambiental que se deseja pesquisar.

A vulnerabilidade ambiental analisa a gênese dos problemas a que os sistemas ambientais são expostos, sob uma ótica da intervenção humana. Visto, que são as ações antrópicas que direta ou diretamente, mudam a dinâmica ambiental e, geralmente, essas ações estão associadas a questões econômicas, bem como habitacionais, oriundas desde o período em que o homem passa a fixar-se em espaços específicos. Necessitando, portanto, manipular os sistemas ambientais (solo, vegetação) para garantir sua sobrevivência.

Desta forma, é notório a relação entre as dimensões sociais e ambientais da vulnerabilidade, tendo em vista, que não existe sociedade sem natureza e nem natureza sem sociedade. Assim, identificando as áreas socialmente vulnerais e analisando se estas sofrem algum problema de caráter ambiental resultaremos em um estudo acerca da Vulnerabilidade Socioambiental.

Os problemas socioambientais são mais expressivos nas cidades. No entanto, Deschamps (2009) evidencia a dificuldade ou ineficiência da administração das cidades em lidar com os problemas ambientais decorrentes de processos de urbanização, que resultam de uma ocupação inadequada e o uso indevido de áreas de risco. Seguindo esse pressuposto, a autora enfatiza a necessidade de analisar não só as "desigualdades sociais, mas, também, verificar como estas se associam às situações de desigualdades ambientais".

Segundo Mendonça (2002):

[...] o emprego da terminologia socioambiental não explicita somente a perspectiva de enfatizar o envolvimento da sociedade como elemento processual, mas é também decorrente da busca de cientistas naturais a preceitos filosóficos da ciência social para compreender a realidade numa abordagem inovadora (MENDONÇA, 2002, p.126).

Ao analisar essa nova visão sobre vulnerabilidade, Deschamps (2004) a define como aquela que ocorre quando há a coincidência de vulnerabilidade social e ambiental em uma mesma 
área ou para uma mesma população. A autora destaca ainda, que há uma estreita relação entre a localização espacial dos grupos que apresentam desvantagens sociais e aquelas áreas onde há risco de ocorrer algum evento adverso, ou seja, populações socialmente vulneráveis se localizam em áreas ambientalmente vulneráveis. (DESCHAMPS, 2004, p. 140).

Assim, a vulnerabilidade socioambiental, de acordo com o que considera a autora, pode ser definida como uma área onde coexistem riscos ambientais e populações em situação de vulnerabilidade social. Ou seja, grupos socialmente vulneráveis estão mais susceptíveis a ocuparem áreas ambientalmente vulneráveis.

\section{MATERIAIS E MÉTODOS}

O presente estudo analisou o nível de vulnerabilidade socioambiental na cidade Arapiraca. Para isso, foi utilizado as pesquisas desenvolvidas pelo Atlas da vulnerabilidade social nas regiões metropolitanas brasileiras 2015 (IPEA, 2015), e os trabalhos de Lopes (2013) e Adger (2006). Ambos os trabalhos, evidenciam a criação de critérios e indicadores para chegar ao resultado, denominado Índice de Vulnerabilidade Socioambiental (IVSA).

Posteriormente, para identificar as áreas sociovulneráveis foram utilizados os dados secundários dos Censos Demográficos de 2000 e 2010 disponibilizados pelo Instituto Brasileiro de Geografia e Estatística (IBGE), sendo que o recorte espacial escolhido foi os bairros. Essa escolha, ocorreu pelo fato de o órgão não divulgar as informações por setores censitários. Já para a análise das características ambientais, foram utilizadas imagens de satélites utilizando o software arcgis 10.0. O mapa de relevo e das bacias hidrográficas foi o produto cartográfico utilizado para a delimitação dos indicadores (ocupação da vegetação e ocupação de planícies fluviais) onde, a partir da identificação visual, é possível mensurar as áreas que por ventura foram ocupadas por residências, sendo viável calcular a vulnerabilidade de cada área para os indicadores desse critério.

Para dar suporte à metodologia utilizou-se, os parâmetros de seleção de indicadores de Adger (2006), no qual o autor classifica os indicadores em três critérios: exposição do sistema; a sensibilidade do sistema e a capacidade de resposta ou adaptativa do meio.

1) A exposição do sistema, em que foram avaliados os indicadores que compreendem o risco ambiental, mostram a pressão antropogênica exercida no sistema, como ocupação da vegetação e ocupação da planície fluvial.

2) A sensibilidade do sistema às pressões exercidas, no qual foi avaliado os indicadores da dimensão risco social (Tabela 1), que mostram as características da população (educação, renda, 
entre outras). Sendo essas, as características que demostram a fragilidade, que um grupo apresentará a um evento que poderá causar um dano.

3) A capacidade de resposta do meio, avalia a dimensão infraestrutura urbana dada pela relação entre as condições estruturais urbanas e a conservação ou preservação ambiental, que tem influência significativa nos possíveis efeitos das pressões exercidas na área analisada.

Adger (2006) ressalta que, quanto maior for a exposição e as pressões que o ambiente esteja sofrendo ou venha a sofrer, maior será a sua sensibilidade e menor a sua capacidade de resposta, o que indica que a área em estudo está vulnerável a problemas, tanto de cunho social como ambiental. A tabela 1, mostra a relação dos indicadores, bem como qual dimensão e critério cada um pertence.

Tabela 1: Relação das Dimensões, Indicadores e Critérios a serem mensurados para a Vulnerabilidade Socioambiental da cidade de Arapiraca/AL.

\begin{tabular}{|c|c|c|}
\hline DIMENSÕES & INDICADORES & CRITÉRIOS \\
\hline RISCO AMBIENTAL & $\begin{array}{l}\text { - Ocupação da vegetação }-\mathbf{O V} \\
\text { Ocupação da planície fluvial } \\
\text { OPF. }\end{array}$ & EXPOSIÇÃO \\
\hline RISCO SOCIAL & $\begin{array}{l}\text { - } \quad \text { Crianças entre 5-9 anos sem estar } \\
\text { na escola - CSE; } \\
\text { - Jovens entre 10-14 anos sem estar } \\
\text { na escola - JSE; } \\
\text { - } \quad \text { Pessoas analfabetas - PA; } \\
\text { - } \quad \text { Domicílios próprios - DP; } \\
\text { - } \quad \text { Relação de dependência - RD; } \\
\text { Razão de moradores por } \\
\text { domicílio - RM; }\end{array}$ & SENSIBILIDADE \\
\hline $\begin{array}{c}\text { INFRAESTRUTURA } \\
\text { URBANA }\end{array}$ & $\begin{array}{l}\text { - } \quad \text { Renda per capita }-\mathbf{R} \text {. } \\
\text { - } \quad \text { Abastecimento de água }-\mathbf{A A} ; \\
\text { - } \quad \text { Rede de esgoto }-\mathbf{R E} ; \\
\text { - } \quad \text { Coleta de lixo } \mathbf{C L} \text {. }\end{array}$ & $\begin{array}{l}\text { CAPACIDADE DE } \\
\text { RESPOSTA }\end{array}$ \\
\hline
\end{tabular}

Com o estabelecimento dos indicadores, foi mensurada uma média aritmética para cada um, sendo extraída pela relação do valor atribuído para cada bairro dividido pelo valor total da cidade, como mostra a equação a seguir:

$$
V I B=\frac{T I B}{T C}
$$

$\mathrm{VIB}=$ Valor do Indicador do Bairro.

$\mathrm{TIB}=$ Total do Indicador do Bairro.

$\mathrm{TC}=$ Total da Cidade.

Após a normatização de cada critério e seus respectivos indicadores, foi atribuído o valor em escala que varia de 0,01 (valor mínimo) e 1,00 (valor máximo). A normalização dos 
indicadores, proposta nessa pesquisa, recebeu uma escala de valores para mensurar os resultados, como é apresentado na tabela 2.

Tabela 2: Níveis, valores e cores para o nível de vulnerabilidade da cidade de Arapiraca/AL.

\begin{tabular}{ccc}
\hline Níveis & Valores & Cores \\
\hline Muito baixa & $0,81-1,00$ & \\
Baixa & $0,61-080$ & \\
Média & $0,41-0,60$ & \\
Alta & $0,21-0,40$ & \\
Muito alta & $0,01-0,20$ & \\
\hline
\end{tabular}

Fonte: Autores, 2018.

Como mostra a tabela 2 , os valores próximos a 0,0 (zero) correspondem a uma vulnerabilidade muito alta e quando os valores estiverem próximos a 1,0 (um) equivalem a uma vulnerabilidade muito baixa.

Tomando como base a equação 1, o nível de vulnerabilidade do critério exposição estão elencados como indicadores ambientais: a ocupação da vegetação - que corresponde a áreas ocupadas por vegetações remanescentes sejam elas nativas ou não. E a ocupação da planície fluvial - que corresponde a áreas em torno de rios ocupadas pelo homem para os seus diversos fins. Para o cálculo desse indicar foi realizada a soma do valor encontrado para os indicadores (OV e OPF) dividido pelo número total de indicadores 2 (dois), como mostra a equação 2 :

$$
\text { IVSAe }=\frac{O V+O P F}{2}
$$

IVSAe= Índice de Vulnerabilidade Socioambiental do critério de exposição a riscos ambientais.

OV - Ocupação da Vegetação.

OPF - Ocupação da Planície Fluvial.

Os valores para análise da vulnerabilidade desse critério seguiram os parâmetros: IVSAe = 0,01-0,20 muito alta; 0,21-0,40 alta; 0,41-0,60 média; 0,61-0,80 baixa; e 0,81-1,00 muito baixa.

Para obtenção dos valores, os indicadores da dimensão risco social (CSE, JSE, PA, DP, $\mathrm{RD}, \mathrm{RM}, \mathrm{R})$, que fazem parte da classe de vulnerabilidade social, foi utilizada a equação 3 , que apresenta a soma do valor encontrado para cada indicador dividido pelo número total de indicadores 7 (sete).

$$
I V S A S=\frac{C S E+J S E+P A+D P+R D+R M+R}{7}
$$

IVSAs - Índice de Vulnerabilidade Socioambiental do critério sensibilidade.

CSE - Crianças entre 5-9 anos sem estar na escola.

JSE - Jovem entre 10 - 14 anos sem estar na escola.

PA - Pessoas analfabetas.

DP - Domicílios próprios.

RD - Relação de dependência.

RM - Razão de moradores por domicílios.

$\mathrm{R}$ - Renda per capita. 
Entretanto, é importante destacar, que diferente do critério de exposição e capacidade de respostas a sensibilidade tem seus valores invertidos, foi feito uma adaptação, sendo considerado vulnerabilidade muito alta quando os valores estão próximos a 1,0 (um) e vulnerabilidade muito baixa próximo a 0,0 (zero). Para analisar o IVSAs, é feito uma adaptação, considerando os seguintes parâmetros: IVSAs $=0,01-0,20$ muito baixa; 0,21-0,40 baixa; 0,41-0,60 média; 0,61-0,80 alta; e 0,81-1,00 muito alta;

Assim como as demais equações, o Índice de Vulnerabilidade Socioambiental do critério capacidade de resposta faz uma adaptação da fórmula da equação 1. Como mostra a equação 4, é feita a soma do valor encontrado para os indicadores (AA, ES e CL) dividido pelo número total de indicadores 3 (três).

$$
I V S A r=\frac{A A+E S+C L}{3}
$$

IVSAr - Índice de Vulnerabilidade Socioambiental do critério de capacidade de resposta.

AA - Abastecimento de água.

$\mathrm{RE}$ - Rede de esgoto.

CL - Coleta de lixo.

Os valores para análise da vulnerabilidade desse critério seguiram os parâmetros estabelecidos como: IVSAr = 0,01-0,20 muito alta; 0,21-0,40 alta; 0,41-0,60 média; 0,61-0,80 baixa; 0,81-1,00 muito baixa.

Por fim, para construir o Índice de Vulnerabilidade Socioambiental (IVSA) de Arapiraca, foi mensurado, a partir da média aritmética dos índices de vulnerabilidade em cada dimensão, critério e classe, conforme a equação 5. Conforme a equação abaixo, é feita uma soma dos valores encontrados para cada critério (IVSAe + IVSAs + IVSAcr) dividido pelo número total de critérios estabelecidos, no caso 3 (três).

$$
I V S A=\frac{I V S A e+I V S A S+I V S A C r}{3}
$$

IVSA = Índice de Vulnerabilidade Socioambiental.

IVSAe = Índice de Vulnerabilidade Socioambiental do critério de exposição a riscos ambientais.

IVSAs = Índice de Vulnerabilidade Socioambiental do critério sensibilidade.

IVSAcr $=$ Índice de Vulnerabilidade Socioambiental do critério Capacidade de Resposta.

O cálculo dessa última equação, atribuiu o valor final da análise da vulnerabilidade socioambiental da cidade, os valores assim como o critério de sensibilidade têm seus valores invertidos, isto é, após cálculos de alguns indicadores verificou-se que os resultados aferidos, alguns indicadores tiveram valores investidos. Pois segundo a tabele 2 , os indicadores se dividiam em classes e valores que variavam de 0,00 (muito baixa) a 1,00 (muito alta) vulnerabilidade.

Entretanto, devido trabalharmos com valores do IBGE por bairros e não por setores censitários, alguns indicadores tiveram seus valores modificados, e os autores necessitaram adaptar alguns valores para classes e valores para não comprometer o resultado da pesquisa. Assim, o IVSA 
seguiu os seguintes parâmetros: IVSA $=0,01-0,20$ muito baixa; 0,21-0,40 baixa; 0,41-0,60 média; 0,61-0,80 alta; e 0,81-1,00 muito alta.

Finalizada o cálculo e com a construção do IVSA da cidade o poder público seja e as entidades que demonstrarem interesse pela cidade terão na presente proposta uma forma de subsídio para que possam direcionar suas ações e a aplicação de políticas públicas, com o intuito de promover o desenvolvimento para a comunidade sob investigação.

\section{RESULTADOS E DISCUSSÕES}

A criação do IVSA da cidade de Arapiraca foi o resultado da análise conjunta de cada indicador distribuídos entre os três critérios estabelecidos por Adger (2006), sensibilidade, exposição e capacidade de resposta. De acordo com o autor, esses critérios podem sintetizar o quão é vulneral uma localidade, através da associação e relação entre eles. Pois quanto maior for a exposição e as pressões que o ambiente esteja sofrendo ou venha a sofrer, maior será a sua sensibilidade e menor a sua capacidade de resposta.

Concomitantemente observou-se que os indicadores em situação crítica, são aqueles dos critérios de exposição e capacidade de resposta, especificamente os indicadores de área com menor ocupação de vegetação, área com maior ocupação de construções em planícies fluvial (critério de exposição) e esgotamento sanitário (critério de capacidade de resposta).

Os indicadores área com menor ocupação de vegetação e área com maior ocupação de construções em planícies fluvial, são os únicos do critério de "exposição", logo esse critério foi o que mostrou o nível mais elevado de vulnerabilidade. A figura 2, espacializa a ocupação da vegetação, na cidade de Arapiraca.

Um fator responsável pela retirada da vegetação segundo Leite (2012), como mostra a figura 2, é a especulação imobiliária, vinculado ao crescimento populacional da cidade de Arapiraca, fenômeno posterior ao caráter agrícola que a cidade possui durante o auge da produção de fumo. A falta de vegetação e ocupação inadequada das vertentes dos córregos que corta a região urbana de Arapiraca gera problemas ambientais e social como inundações.

Paralelamente a situação do critério de exposição, os sete indicadores do critério de sensibilidade, apontaram para uma variação positiva, na série comparativa entre os anos estudados. Em 2000, para o critério de sensibilidade a cidade encontrava-se no nível de Média Vulnerabilidade, em contrapartida após dez anos com adoção de medidas de melhoria na oferta de serviços públicos (saúde, educação, entre outros) e programas de distribuição de renda, em 2010 Arapiraca já se deparava no nível de Baixa Vulnerabilidade. 


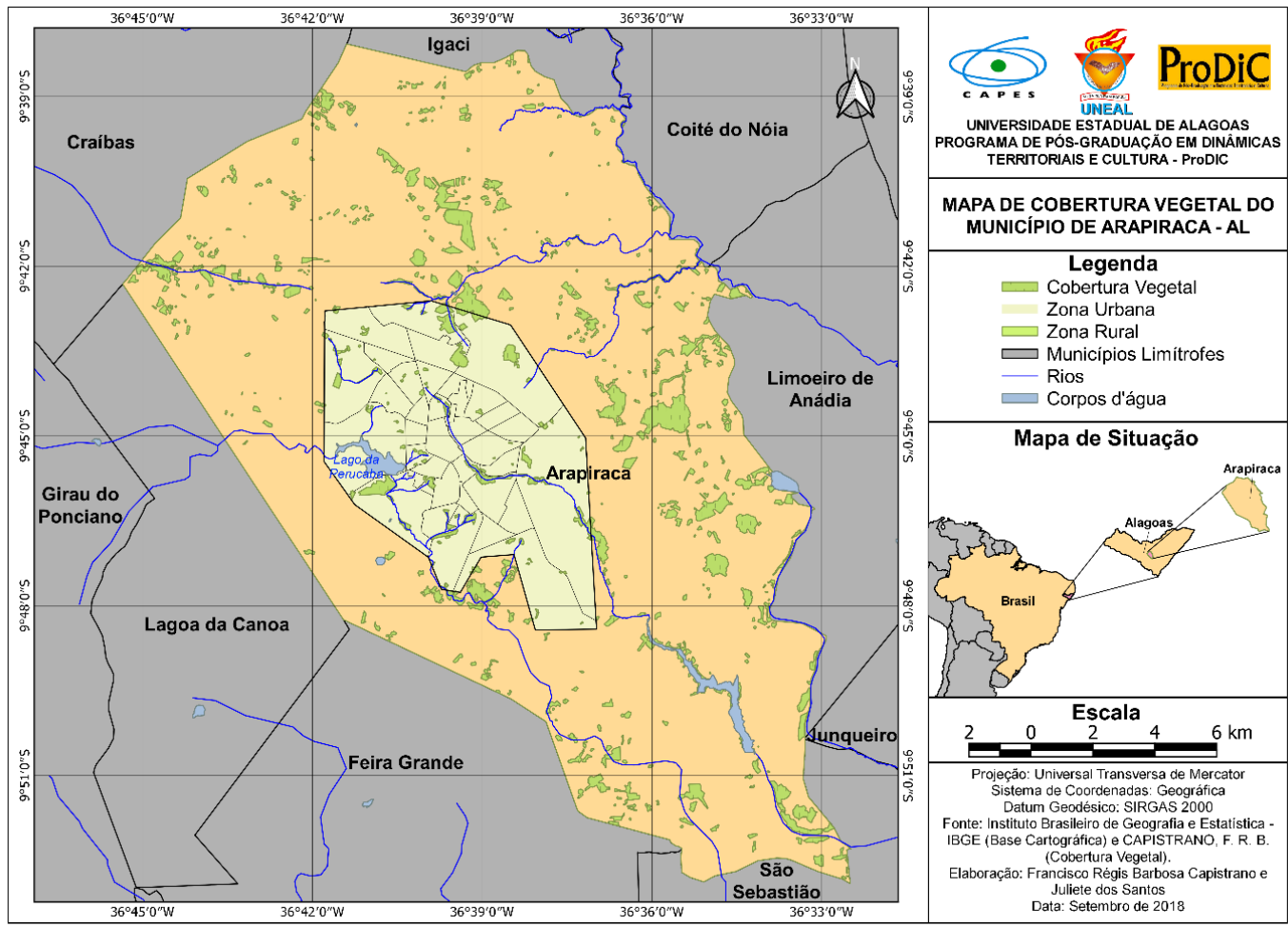

Figura 2 - Cobertura Vegetal do Município de Arapiraca- AL (2010). Fonte: Autores, 2018.

Conforme, os resultados obtidos pelo critério de capacidade de resposta da dimensão infraestrutura urbana, que avaliaram a qualidade habitacional da população. $O$ indicador esgotamento Sanitário, evidenciou as condições precárias na oferta do serviço, no qual, a maioria dos bairros não possui seu esgoto ligado a uma rede geral. Porém esse critério na sua conjuntura não é preocupante, visto que dos quatro indicadores apenas o esgotamento sanitário foi avaliado negativamente. Assim, o nível de vulnerabilidade para o critério de capacidade de resposta foi de Média Vulnerabilidade.

Para entender de que forma os resultados foram impactados vale ressaltar que o ordenamento territorial é necessário ao pleno cumprimento da "função social, como consequência de um processo histórico de sucessão de modelos socioeconômicos pautados, em boa parte, pela supressão da maioria" (PEREIRA, 2009, p. 20), com a premissa de minimizar as desigualdades espaciais do ambiente urbano e aperfeiçoar a ação do poder público local.

Pereira (2009), enfatiza que o crescimento desordenado das cidades, causa diversos problemas de ordem social que vão, impreterivelmente, interferir nas questões ambientais. Todo esse contingente e correlação evidenciam a dificuldade ou ineficiência da administração das cidades em lidar com os problemas ambientais e sociais advindos da oferta ineficiente da infraestrutura urbana necessária.

Em consequência da avaliação quantitativa dos três critérios é possível aferir a partir do mapa final da Vulnerabilidade Socioambiental de Arapiraca, que a cidade não apresenta níveis 
elevados de vulnerabilidade socioambiental. A seguir, em decorrência da apreciação comparativa das figuras 3 e 4 é possível identificar o referido fato.

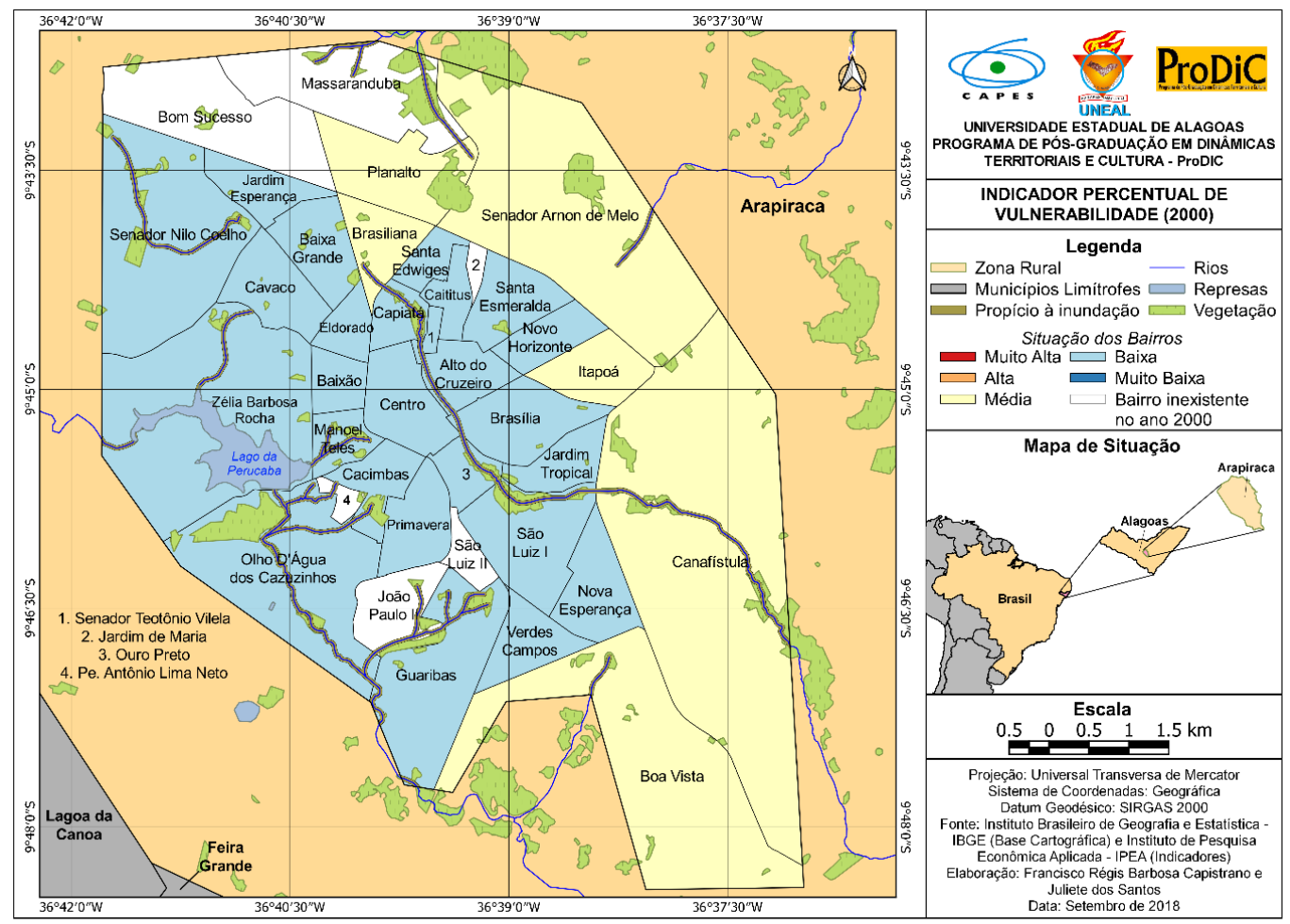

Figura 3 - Percentual de Vulnerabilidade (2000).

Fonte: Autores, 2018.

Em 2000, como exposto na figura 3, dos 33 bairros, 6 estavam inseridos no nível de Média Vulnerabilidade, estando os demais 27 bairros no nível de Baixa Vulnerabilidade. É possível observar, que os bairros que estavam inseridos nos níveis de valores menores, são bairros periféricos que ainda possuem características e traços da zona rural, ou seja, bairros que ainda necessitam de investimentos em diversas áreas, símbolo do processo gradual e contínuo de expansão e atualização da zona urbana de Arapiraca.

No ano de 2010 foi registrado o aumento no perímetro urbano, bem como a mudança de nomenclatura de alguns bairros. O único bairro que estava na classe de Média vulnerabilidade, era o bairro Massaranduba que, em 2000, não fazia parte do perímetro urbano de Arapiraca.

Ou seja, é um bairro que está em processo de estruturação e que, inevitavelmente, apresenta algumas dificuldades resultantes desse processo de estruturação. A figura 4, retrata a evolução do município se comparado com o ano de 2000.

Comparando os dados dos anos estudados, é possível perceber que Arapiraca é uma cidade que apresenta baixa vulnerabilidade, de acordo com os indicadores verificados. No entanto, é visível a intensa relação e influência do processo de crescimento populacional e a dinâmica urbana nos indicadores que avaliam a dimensão risco ambiental (Ocupação da vegetação e Ocupação da 
planície fluvial). Mostra que a degradação do meio se estabelece, a parir do desenvolvimento das atividades humanas, como o uso e ocupação do solo.

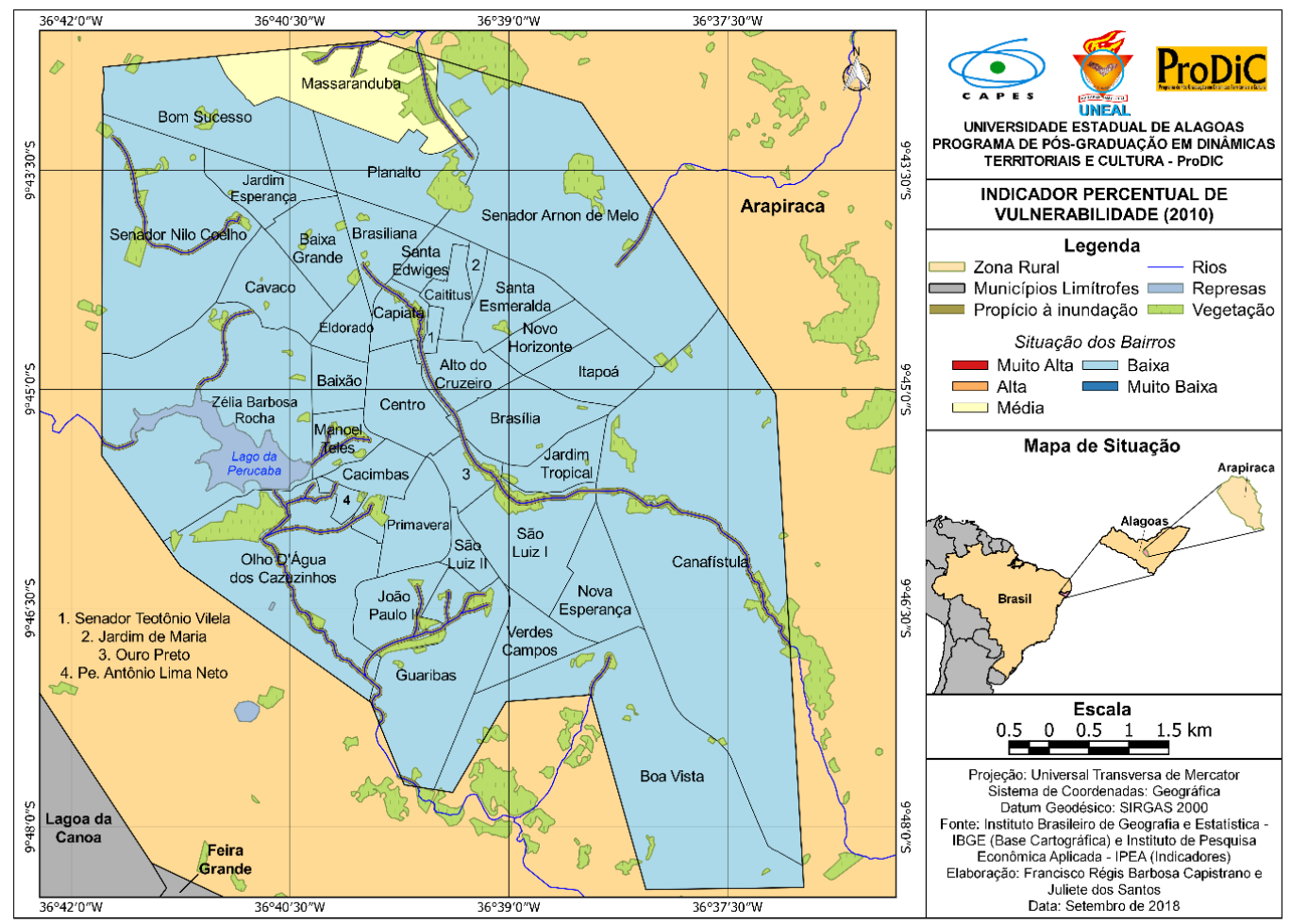

Figura 4 - Percentual de Vulnerabilidade (2010).

Fonte: Autores, 2018.

Sendo perceptível, que aos bairros que apresentaram mais problemas com relação aos indicadores das três dimensões (Risco ambiental, risco social e infraestrutura urbana) são bairros que possuem criação mais recente, que ainda não conseguem atender as necessidades da população, ou seja, estão em processo de estruturação.

\section{CONCLUSÃO}

O critério que influência decisivamente no Índice Vulnerabilidade Socioambiental de Arapiraca-AL, é o de sensibilidade. Esse critério, avalia a dimensão risco social, com as características da população, com o intuito de demostraram a fragilidade, quando exposto a um dano, possui a maior quantidade de indicadores, sete no total. Os valores obtidos por cada indicador foram satisfatórios e inevitavelmente se sobressaíram em relação aos demais mediante o aferimento dos dados e principalmente devido a sua forma de divulgação porque o IBGE disponibiliza os dados da cidade de Arapiraca por bairro e não por setor censitário.

Os resultados obtidos neste estudo constataram que a cidade de Arapiraca apresenta, predominantemente, níveis de vulnerabilidade socioambiental de baixo a médio (com valores entre 
0,21 a 0,40 de Baixa Vulnerabilidade a 0,41 a 0,60 de Média Vulnerabilidade). Decorrente de fatores sociais e ambientais, a mensuração final do IVSA foi de 0,35.

Conclui-se que Arapiraca apresenta a relação enfatizada por Deschamps (2004), em que populações socialmente vulneráveis tendem a se localizar em áreas ambientalmente vulneráveis e estando susceptíveis a riscos e perigos. Esses casos expõem que tal condição de vulnerabilidade, em alguns aspectos, está condicionada ao uso que se faz da área, sendo ou não de interesse social e principalmente econômico. Esse fato pode evidenciar o importante papel da dinâmica econômica na modificação dos aspectos socioambiental da cidade.

A respeito da metodologia aplicada, foi possível mapear e traçar o perfil de Arapiraca em relação à sua cobertura vegetal, condição social e infraestrutura dos bairros. A análise permitiu identificar os bairros que necessitam de uma intervenção do poder público, sendo a presente pesquisa um importante instrumento para a elaboração de políticas voltadas ao ordenamento territorial municipal. Como destaca Birkmann (2006), a sobreposição dos dados permitiu uma análise sistêmica a respeito da exposição física aos perigos naturais e a susceptibilidade social a esses processos. Assim, o Índice de Vulnerabilidade Socioambiental (IVSA), está longe de ser um trabalho que represente de fato a real dimensão das classes de vulnerabilidade, necessitando de aprimoramentos e alternativas de operacionalização do conceito de vulnerabilidade, assim como a inclusão de outras variáveis de avaliação da vulnerabilidade.

\section{REFERÊNCIAS}

ADGER, W. N. Vulnerability. Global Environmental Change, v. 16, p. 268-281, 2006.

BIRKMANN, J. (Ed.) Measuring Vulnerability to Natural Hazards. Towards Disaster Resilient Societies. New York: UNU-Press, 2006. 524p.

DESCHAMPS, M. V. Vulnerabilidade socioambiental na Região Metropolitana de Curitiba. 2004. 192 f. Tese (Doutorado em Meio Ambiente e Desenvolvimento) - Universidade Federal do Paraná, Curitiba, 2004.

. Observatório das Metrópoles. IPPUR/FASE, 2009.

IBGE. Censo Demográfico, 1991. Disponível em: http://www.ibge.gov.br/. Acesso em: 12 dez. 2016. 2016.

. Censo Demográfico, 2000. Disponível em: http://www.ibge.gov.br/. Acesso em: 12 dez.

Censo Demográfico, 2010. Disponível em: http://www.ibge.gov.br/. Acesso em: 12 dez. $\overline{2016 .}$ 
IPEA. Atlas da vulnerabilidade social nos municípios brasileiros. Editores: Marco Aurélio Costa, Bárbara Oliveira Marguti. - Brasília, 2015. Disponível em: http://ivs.ipea.gov.br/images/ publicacoes/Ivs/publicacao atlas ivs.pdf. Acesso em: 12 dez. 2016.

LEITE, A. M. A. O Município de Arapiraca/AL e sua Dinâmica Histórica de Ocupação e Renda, 2012.17p.

LIVERMAN, D. M. Vulnerability to global environmental change. In: CUTTER, S. L. Environmental risks and hazards. London: Prentice-Hall, 1994. p. 326-342.

LOPES, J. L. S. Proposta de indicadores de sustentabilidade aplicado para o estudo da vulnerabilidade da comunidade de Batoque-Aquiraz/CE. 2013. 153 f. Tese (Doutorado em Geografia) - Universidade Federal do Ceará, Fortaleza, 2013.

MARANDOLA JR., E.; HOGAN, D. J. Vulnerabilidades e riscos: entre geografia e demografia. Revista Brasileira de Estudos de População, São Paulo, v. 22, n. 1, p. 29-53, 2005.

MENDONÇA, F. Geografia socioambiental. In: MENDONÇA, F.; KOZEL, S. (Orgs). Elementos de epistemologia da geografia contemporânea. Curitiba: UFPR, 2002. 265p.

MENDONÇA, F. A.; LEITÃO, S. A. M. Riscos e vulnerabilidade socioambiental urbana: uma perspectiva a partir dos recursos hídricos. GeoTextos, v. 4, n. 1, p. 145-163, 2008.

MITCHELL, J. K. Hazards research. In: GAILE, G. L.; WILLMOTT, C. J. Geography in America. Columbus: Merrill, 1989. p. 410-424.

MORAIS, O. M.; LIMA, B.; NASCIMENTO, V. F. V.; FERRO, T. P. P. Uso Corporativo do Território e a Industrialização em Arapiraca - AL. In: CONGRESSO BRASILEIRO DE GEÓGRAFOS. 7., 2014, Vitória. Anais... Vitória: AGB, 2014. p. 1-10.

PEREIRA, R. R. Planejamento Territorial: suas implicações para a promoção da saúde e da justiça ambiental. GEOUSP: Espaço e Tempo, São Paulo, n. 26, p. 19 - 27, 2009.

PMA. Prefeitura Municipal de Arapiraca. Coordenação para Elaboração da Agenda 21. Relatório das características ambientais do município de Arapiraca-AL. Secretaria Municipal de Desenvolvimento Urbano e Meio Ambiente - SEDUMA, 2007. 114p.

SOUZA, M. L. ABC do Desenvolvimento Urbano. 2. ed. Rio de Janeiro: Bertrand Brasil, 2005. 192 p.

ZANEllA, M. E.; COSTA, M. C. L.; PANIZZA, A. C.; ROSA, S. V. Vulnerabilidade socioambiental de Fortaleza. In: DANTAS, E.; COSTA, M. C. L. (Orgs). Vulnerabilidade socioambiental: na região metropolitana de Fortaleza. Fortaleza: Edições UFC, 2009. cap. 8, p. 191-216. 